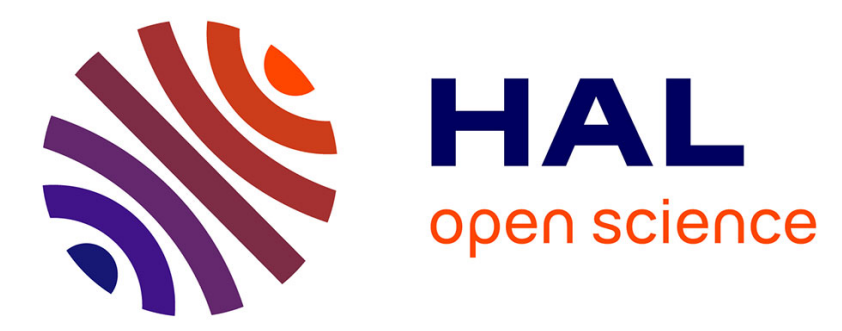

\title{
Influence of the stacking sequence on the low-energy impact resistance of flax/PA11 composite
}

Yann Lebaupin, Thuy-Quynh Truong, Michaël Chauvin, Fabienne Touchard

\section{To cite this version:}

Yann Lebaupin, Thuy-Quynh Truong, Michaël Chauvin, Fabienne Touchard. Influence of the stacking sequence on the low-energy impact resistance of flax/PA11 composite. Journal of Composite Materials, 2019, 53 (22), pp.3187-3198. 10.1177/0021998319837339 . hal-02336870

\section{HAL Id: hal-02336870 \\ https://hal.science/hal-02336870}

Submitted on 17 Nov 2020

HAL is a multi-disciplinary open access archive for the deposit and dissemination of scientific research documents, whether they are published or not. The documents may come from teaching and research institutions in France or abroad, or from public or private research centers.
L'archive ouverte pluridisciplinaire HAL, est destinée au dépôt et à la diffusion de documents scientifiques de niveau recherche, publiés ou non, émanant des établissements d'enseignement et de recherche français ou étrangers, des laboratoires publics ou privés. 


\title{
INFLUENCE OF THE STACKING SEQUENCE ON THE LOW-ENERGY IMPACT RESISTANCE OF FLAX/PA11 COMPOSITE
}

\author{
Yann Lebaupin ${ }^{(1)}$, Thuy-Quynh Truong Hoang ${ }^{(2)}$, Michaël Chauvin ${ }^{(2)}$, Fabienne
} Touchard $^{(3)}$

(1) Laboratory for Processing of Advanced Composites (LPAC), Institute of Materials, Ecole Polytechnique Fédérale de Lausanne (EPFL), CH-1015 Lausanne, Switzerland

${ }^{(2)}$ ESTACA'LAB, Pôle Mécanique des Structures Composites et Environnement (MSCE), ESTACA - Campus Ouest, Rue Georges Charpak, BP 76121, 53061 Laval Cedex 9, France

${ }^{(3)}$ Institut PPRIME, ENSMA, CNRS UPR3346, BP 40109, 86961 Futuroscope Cedex, France

\section{Keywords}

Flax, Polyamide 11, Impact behavior, Damage mechanisms, Absorbed energy

\begin{abstract}
In this paper, the low-energy impact behavior of a fully biobased composite made of biosourced polyamide 11 resin reinforced with flax fibers was investigated. Different composite laminates were studied in order to determine the stacking sequence effects on the impact behavior of these composites. Four stacking sequences were manufactured: unidirectional $\left[0^{\circ}\right] 8$, cross-ply $\left[0^{\circ} / 90^{\circ}\right]_{2 \mathrm{~s}}$, sandwich-like $\left[02^{\circ} / 90_{2}^{\circ}\right]_{\mathrm{s}}$ and quasi-isotropic $\left[45^{\circ} / 0 /-45^{\circ} / 90^{\circ}\right] \mathrm{s}$. A low impact energy of 3.6 J was applied on these laminates by means of a drop weight impact tower. The impact properties of these lay-ups were ascertained by analysing the impact load history, the maximal displacement of the impactor and the absorbed energy. Damage after impact was further assessed by visual inspections, topographic measurements, C-scan and X-ray micro-
\end{abstract}


tomography observations. The results show that impact damage of composite plates is highly influenced by fiber orientation. The impact test data are in good agreement with damage analysis after impact and indicate that stacking plies in the same orientation lead to a larger induced damage, which is responsible for energy dissipation. The quasi-isotropic composite has the smallest induced damage and the highest peak load. Otherwise, the sandwich-like sequence shows the lowest peak load, the highest energy absorption and significant induced damage. Therefore, it is necessary to choose the most suitable lay-up, in terms of impact behavior, for each considered industrial application.

\section{Introduction}

By an increasing environmental awareness and governmental sustainability policies and regulations, the interest in polymer composites reinforced with natural fibers has increased in the last few years. Natural fibers have been used to reinforce plastics thanks to their good specific strengths, biodegradability, and low density. Recent papers investigate the use of natural fibers such as jute, sisal, flax for composite reinforcement [1-5]. In most cases, the used resins come from petrochemical industry and are not "eco-friendly" materials. In order to develop a $100 \%$ bio-sourced composite, in this study we use flax fibers combined with a biobased polymer Polyamide 11. This polymer is derived from castor oil [6], it is called Rilsan PA11 and is used in a large number of applications thanks to its outstanding properties: excellent resistance to chemicals, ease to processing, a wide range of working temperature and low density. In the literature, a lot of works have been interested in static behaviour of natural fiber-reinforced composites with petroleum- or bio-sourced resins [7-9] but only few studies focus on their dynamic behavior. However, dynamic behavior is crucial for industrial development of this eco-friendly composite to design new parts which can withstand impact loadings. Low energy impacts that may be induced by falling foreign objects are the most detrimental loadings in composite structures $[10,11]$. Such damage may cause a drastic 
reduction in load bearing capabilities of these "eco-friendly" composites. In this context, the main objective of this paper is to understand the response of flax fibers/PA11 composite subjected to a low energy impact and to analyse the development of induced damage by experimental characterisation.

Low energy impact response of fiber-reinforced composites has been reported in different studies $[12,13]$. Some studies were particularly interested in the influence of processing parameters, as temperature [14], or of composite structure, as voids and moisture that strongly affect their impact behaviour [15]. It has been reported that damage development is influenced by the shape and the weight of the impactor [16], and by the impact energy [17-22]. Finally, the impact resistance can be affected by impact specimen thickness [23, 24], composite density $[25,26]$ and stacking sequences [27-29]. In terms of natural fiber-reinforced composites, some authors have reported low velocity impact investigations in the literature: Dhakal et al. [7-12] dealt with hemp fiber reinforced polyester composites. They used three types of impactor shape and four impact velocities. They found that the major damage occurs in specimens subjected to a conic impactor rather than a hemispherical impactor. The authors studied the effect of fiber volume ratio on impact characteristics of the same composites. They concluded that an increase of hemp fibers ratio by $10 \%$ enhances the impact resistance properties compared to the neat matrix. Other authors have reported the impact properties of composites made of hemp and epoxy or PLA matrix [30]. They noticed that the unidirectional laminate showed a larger damage than the bidirectional specimen when subjected to an impact below $75 \mathrm{~J}$. Woven hemp/epoxy composites were impacted at 2.5, 5 and 10J by de Vasconcellos et al. [31]; the authors demonstrated that the residual tensile strength decreased with impact energy but the elastic modulus was not affected. A recent study of Scarponi et al. [32] dealt with a $100 \%$ biobased composite from bioepoxy resin. They concluded that bioepoxy resin offered the same properties than a conventional epoxy resin. In terms of ply stacking, Fuoss et al. [33] 
investigated its effect on synthetic composite laminate by using a numerical approach. Finite element method was used to predict the damage trends with respect to the stacking sequence. They found that stacking plies in close orientations lay-ups influenced impact resistance and damage area more than the angle between two adjacent plies. Ply grouping was found to reduce the damage resistance in a laminate. It was demonstrated that grouping plies increases bending stiffness and stress concentration at the interfaces and creates larger delamination. Otherwise, Ahmad et al. [15] investigated the effect of stacking sequence on the impact resistance of carbon fiber-reinforced composite under low-velocity impact loading. They used three types of specimens: quasi-isotropic, unidirectional, and cross-ply. They showed that the unidirectional composite has the worst impact resistance and the cross-ply composite exhibited the best resistance. They explained the best resistance of impact in the cross-ply composite by a nonzero coupling matrix. However, from the literature review, there are few reported works that investigate the effect of stacking sequence on the impact performance of natural fiberreinforced composites.

Therefore, the aim of this study is to investigate in detail the effect of stacking sequence on the impact behavior of a $100 \%$ biocomposite made of flax fibers and polyamide 11 . Four stacking sequences with different ply orientations were used for impact test: unidirectional $\left[0^{\circ}\right]_{8}$, crossply $\left[0^{\circ} / 90^{\circ}\right]_{2 \mathrm{~s}}$, sandwich-like $\left[02^{\circ} / 90_{2}^{\circ}\right]_{\mathrm{s}}$ and quasi-isotropic $\left[45^{\circ} / 0 /-45^{\circ} / 90^{\circ}\right] \mathrm{s}$. Drop weight impact tests were performed at the same energy for the four stacking sequences. The impact response was analysed by using the load and displacement curves from the drop weight tower. Three parameters: absorbed energy, maximum displacement and peak load were used to characterize the influence of ply orientations. Moreover, external damage was investigated by visual and topographic measurements. Finally, the failure mechanisms of impact specimens were characterized by ultrasonic C-scan inspection and X-ray micro-tomography observations. 
This work allowed comparing the induced damage in very different types of stacking sequences: alternated, grouped, and with various ply orientations.

\section{Materials and techniques of characterization}

\subsection{Materials}

Composite plates were made from unidirectional (UD) flax fibers and Polyamide 11 (PA11) polymer (Fig.1). UD fabrics were supplied by Depestele company located in Bourguebus (France). They are made of longitudinal fiber tows joined by some transverse flax yarns and have an area weight of $450 \mathrm{~g} / \mathrm{m}^{2}$. Polyamide 11, produced from castor oil, was provided by Arkema industry, located in Serquigny (France), in form of film "LMFO" with a thickness of $100 \mu \mathrm{m}$ and a density of $1.02 \mathrm{~g} / \mathrm{cm}^{3}$. Its melting temperature is $190^{\circ} \mathrm{C}$. Composite plates were then manufactured using the hot-pressing process, with a fiber weight fraction of $50 \%$ and a plate thickness about $4 \mathrm{~mm}$. The Dieffenbacher press that was used has a capacity of 1000 tons. Flax fiber fabrics layers and PA11 film were piled up alternatively and compressed in a mould with dimensions of $450 \times 500 \times 4 \mathrm{~mm}^{3}$. The applied process has been optimized in a previous paper [34]. Composites were compressed at $210^{\circ} \mathrm{C}$, with a pressure of 25 bars during two minutes, 40 bars during two minutes and 65 bars until the end of the process as described in figure 2. Figure 3 shows the four different lay-ups that have been studied: unidirectional $\left[0^{\circ}\right] 8$, cross-ply $\left[0^{\circ} / 90^{\circ}\right]_{2 \mathrm{~s}}$, sandwich-like $\left[02^{\circ} / 90_{2}^{\circ}\right]_{\mathrm{s}}$ and quasi-isotropic lay-up $\left[45^{\circ} / 0 /-45^{\circ} / 90^{\circ}\right] \mathrm{s}$. These lay-ups have the same number of plies (8), the same thickness $(4 \mathrm{~mm})$, the same average fiber volume fraction (44\%) and porosity ratio (9\%).

\subsection{Instrumented Impact Testing}

Impact tests were conducted using IM10, provided by Imatek, located in Herts (United Kingdom), a drop weight tower with a hemispherical striker of $20 \mathrm{~mm}$ diameter. A pneumatic clamping support fixture was used to fix each specimen securely between two rigid plates each containing a $40 \mathrm{~mm}$ diameter circular hole. The striker was moved up to the height of $5.6 \mathrm{~cm}$ 
and then was released at this height with an impact weight of $9.063 \mathrm{~kg}$. The experimental setup is shown in figure 4. This configuration provides an incident energy of 3.6 J. Five specimens were tested for each lay-up, each specimen being impacted once at its center. During the impact, the impact force applied on specimens was measured by a load cell, with a capacity of $30 \mathrm{kN}$, as a function of time and the striker displacement was obtained by a laser sensor. Absorbed energy, maximum displacement and peak load values were used to characterise the impact performance.

\subsection{Topographic measurements}

In order to measure the out-of-plane deformation of the specimens, a "ROMER Absolute Arm with integrated scanner", provided by Hexagon located in WJ Waalre (Netherlands), is used. The size of the investigated area was $80 * 60 \mathrm{~mm}$. Firstly, datum-using points were determined on the non-impacted area to define the flat horizontal surface of samples. In a second time, a laser scanner was used to record the differences between the datum-using points and the points scanned in the impacted area. This technique enabled to measure the profile of impact on the front and rear faces for each stacking sequence surface specimens with a precision of $20 \mu \mathrm{m}$ and a maximum amplitude of $\mathrm{mm}$.

\subsection{C-scan}

The ultra-sound technique was used through transmission inspection air system ULTRAPAC, provided by Mistras-Eurosonic located in Vitrolles (France), and shown in figure 5. The size of the investigated area was $90 * 70 \mathrm{~mm}$. Un-focused piezoelectric transducers of $1 \mathrm{MHz}$ were placed on each side of the sample. The position of the two probes was perfectly aligned in order to receive the maximal signal amplitude. The probes were moved in the $\mathrm{X}$ and $\mathrm{Y}$ positions by the automated scanning machine, $\mathrm{Z}$ was fixed at $1 \mathrm{~cm}$ from the specimen. An ultra-sound $\mathrm{C}$ scan image was realized on each tested specimen. 


\subsection{X-ray micro-CT}

A non-destructive technique, the micro X-ray computed tomography, was also used in order to investigate the internal damage for each type of stacking sequence. Image acquisition has been performed using an Ultratom CT scanner manufactured by RX solution (France). The system consists in a Hamamatsu micro focus sealed X-ray tube operating at $20-150 \mathrm{kV} / 0-500 \mu \mathrm{A}$, within a maximum power of $75 \mathrm{~W}$. A precision object manipulator with two translations and one rotation facilitates rotating the sample for acquisition of tomographic data, and displacement along the optical axis to adjust the magnification. A $14.3 \mu \mathrm{m}$ resolution has been used in this work, with an accelerating voltage of $70 \mathrm{kV}$ and a beam current of $428 \mu \mathrm{A}$. The flat panel detector used in this study has $1920 \times 1536$ pixels with a pixel size of $127 \mu \mathrm{m}$. This X-ray detector consists in an X-ray CsI scintillator screen which is settled on an amorphous silicon layer. The X-ray shadow projections are digitized with 65536 brightness gradations (16 bits) and recorded in TIFF format. The image acquisition time was about $2 \mathrm{~h}$ per specimen. For $3 \mathrm{D}$ reconstruction, X-ray images were acquired from 1440 rotation views over $360^{\circ}$ of rotation $\left(0.25^{\circ}\right.$ rotation step). The reconstruction was performed using an algorithm based on the filtered back-projection procedure for Feldkamp cone beam geometry. Rectangular coupons of $25 \mathrm{~mm}$ wide were cut from the impacted plates.

\section{Experimental results and discussion}

\subsection{Curves of impact behavior}

A number of five tests for each configuration is performed with an impact energy of 3.6J. The representative curve of impact force versus time for each lay-up is shown in figure 6a. A first linear part is observed in the force-time curves for all the lay-ups which corresponds to elastic behavior as commonly reported in literature $[15,31]$. Then the impact load increases gradually to reach the peak level before decreasing continuously up to zero. By comparing impact load histories, one can distinguish two kinds of drop load profile. A higher impact peak load is observed in quasi-isotropic and cross-ply lay-ups compared to unidirectional and sandwich-like 
lay-ups. In addition, the impact load decreases constantly and rapidly in these two lay-ups. On the other hand, the sandwich-like and unidirectional specimens exhibit a progressive load drop characterized by a longer contact time. In fact, the contact time of unidirectional and sandwichlike specimens are respectively 16 and $20 \mathrm{~ms}$. According to the literature, the differences in maximum force can be due to different induced failure modes: matrix cracking, delamination, fiber breakage and fiber splitting and these damage mechanisms usually interact with each other [11].

The impact load versus displacement curves for the four stacking sequences are shown in figure 6b. The area under each load-displacement curve represents the absorbed energy, which is transferred to the composite lay-up during the impact event. In this figure, the first part of the curves shows similar linear slope for all lay-ups. Then, the load reaches a maximum value before decreasing in the second part. For the unidirectional, cross-ply and quasi-isotropic layups, the force-displacement curves decrease rapidly while displacement is diminishing. For sandwich-like specimen, the displacement increases monotonically with decreasing load. Indeed, it is observed for this lay-up that the striker kept moving down, which explains the increasing displacement.

In order to compare the impact performance of the different lay-ups, the values of maximum load and displacement are reported in figure $7 \mathrm{a}$ and $7 \mathrm{~b}$. In these figures, one can conclude that the quasi-isotropic lay-up reaches the highest value of the maximum load, which is about 2.1 $\mathrm{kN}$, while the sandwich-like lay-up has the lowest one, which is about $1.3 \mathrm{kN}$. In figure $7 \mathrm{~b}$, the maximum displacement value of $3.7 \mathrm{~mm}$ is obtained for the sandwich-like sequence. On the opposite, the smallest maximum displacement values are obtained for cross-ply and quasiisotropic lay-ups. Figure 7c describes the energy ratio between absorbed energy and applied energy for all the studied composites. The absorbed energy is determined by the difference between applied energy and rebound energy, which is calculated from the velocity of the striker 
before and after impact. Energy ratios, $97 \%$ and $99 \%$ respectively, are found to be higher in the unidirectional and sandwich-like lay-ups than in other configurations. It shows that the unidirectional and sandwich lay-ups are able to absorb higher impact energy than the other configurations. In conclusion, the sandwich-like and unidirectional specimens exhibit a longer impact duration, maximum displacement values and a greater energy absorption than the crossply and quasi-isotropic ones.

\subsection{External damage of impacted composites}

Macroscopic observations of the front and rear sides of the four different lay-ups are given in figure 8. In the unidirectional and the sandwich-like stacking sequences, a hemispheric damage around the impact point in the front side can be seen by visual inspection. The striker goes through these composite plates leading to the composite penetration characterized by a disbonding of the external ply at the rear side (Fig.8c). On the other hand, for the cross-ply and the quasi-isotropic samples (Fig.8b and d), there is less damage visible in the front sides than for the other lay-ups. However, macro cracks are observed in the external layer in the rear sides. These cracks are oriented parallel and perpendicular to the fiber direction of the external ply

(Fig. $8 \mathrm{~b}$ and d). This phenomenon has also been observed by Vieille et al. [10] in carbonreinforced composites.

In order to get a quantitative profile of the damage, specimens are scanned by topographic measurement after impact as presented in figure 9. The same tendency as the one obtained with macroscopic observation is found when comparing these four cartographies. Firstly, the crossply and quasi-isotropic lay ups are slightly indented in the front side with a maximum height of respectively -0.38 and $-0.41 \mathrm{~mm}$. For the sandwich-like composite, a maximum penetration value of $-3.8 \mathrm{~mm}$ is measured on the front side which correlates with the highest maximum impactor displacement value shown in figure $7 \mathrm{~b}$. Concerning the rear faces, we observe a 
pyramidal shape in the unidirectional lay-up. The deflection in the rear side increases up to +4.0 $\mathrm{mm}$ in the sandwich-like specimen; the white area shows a perforation zone in which the material is completely destroyed. Moreover, small deflections are measured in the rear side respectively from +0.7 to $+0.9 \mathrm{~mm}$ in the cross-ply and the quasi-isotropic laminates.

\subsection{Internal damage of impacted composites}

The ultrasonic analysis is used to evaluate damage area for each stacking sequence and results are presented in figure 10. Damage comparison can be made through intensity and size of detected areas in C-scan cartographies. Indeed, amplitude maps allow visualizing delamination zones. In the unidirectional laminate, the impact area is a circular zone and looks like the hemispherical impactor shape. There is a large red-brown damage area in the center of the specimen and a yellow surrounding damage around the impact zone. For the sandwich-like composite, the damaged area has not a circular shape and measured about $40 \mathrm{~mm} * 30 \mathrm{~mm}$ whereas the diameter of the impactor is only $20 \mathrm{~mm}$. The non-circular damage zone can be explained by the fact that the plate was subjected to an out-of-plane perforation. The observation reveals more severe damage in the interior of the sandwich-like lay-up. For the cross-ply and the quasi-isotropic lay-ups, the damage is less extended than for the two other lay-ups.

In order to distinguish internal from visible damage, the impacted specimens are further inspected by micro-tomography as reported in figure 11. In this figure, for each lay-up, two perpendicular views extracted in the middle of the impacted specimens are shown, in $\mathrm{X}$ and $\mathrm{Y}$ directions.

The unidirectional and sandwich-like lay-ups show more extended damage than other plates

(Fig11.a and c). In view 1 for the unidirectional sample (X slice), which is perpendicular to fiber tows, numerous cracks are observed along specimen thickness, forming a conical shape. 
In the Y slice (view 2), parallel to fiber tows, it can be clearly noticed that a delamination occurred in the middle of the specimen thickness. This observation is in good agreement with the study conducted by Lachaud on carbon-reinforced composites [35]. Regarding the sandwich-like specimen, multiple damage leading to perforation are reported in figure $11 \mathrm{c}$. In the top surface, a local indentation is visible in both slices $\mathrm{X}$ and $\mathrm{Y}$ and extensive damage propagates conically through the thickness of the plate. For the cross-ply lay-up (Fig11.b), fewer cracks are developed in particular in the bottom surface. These micro-cracks go through specimen thickness and seem to be stopped at the $90^{\circ}$ ply in view 1 and at $0^{\circ}$ in view 2 . Indeed, changing fiber orientation from one ply to another limits crack propagation, as it has been shown for synthetic composites [36]. Concerning the quasi-isotropic specimen (Fig11.d), damage is less significant in both slices comparing to other configurations. The $45^{\circ}$ ply participates to restrict crack propagation, confining damage in the middle of the specimen thickness and leading to a delamination at $90^{\circ} \mathrm{ply}$. These results demonstrate that by alternating fiber orientation in adjacent plies, damage propagation during impact tests for flax-reinforced composites can be stopped, or at least limited. Therefore, the choice of the stacking sequence will depend on the objective: the quasi-isotropic lay-up should be preferred in order to limit the impact damage development, but the sandwich-like one has to be chosen for a higher value of absorbed energy.

\section{Conclusion}

In this paper, the low energy impact performance of a bio-composite made of flax fibers and biobased PA11 was investigated. The aim of this study was to analyse the influence of stacking sequences on the impact resistance of this composite. Four different stacking sequences: unidirectional, cross-ply, sandwich-like and quasi-isotropic lay-ups were impacted at 3.6J. Damage induced in the composites were analyzed by visual and topographic observations, 
ultrasonic C-scan and micro-tomography analysis. The load and displacement history curves reveal that the cross-ply and the quasi-isotropic lay-ups possess higher peak load values and lower maximum displacement and absorbed energy levels compared to the two other lay-ups (unidirectional and sandwich-like ones). In particular, the sandwich-like lay-up shows the highest absorbed energy value. It is also observed that fibers of the same orientation stacked in adjacent plies such as in unidirectional or sandwich-like lay-ups induce more significant damage than in the two other configurations. According to ultrasonic C-scan and microtomography analyses, we can confirm that damage can be reduced in flax/PA11 composites by introducing alternated orientations of fibers in laminate sequences. These results give a starting point in the design process of industrial fully biobased composite parts. Moreover, work is in progress for studying the water ageing influence on impact properties for these green composites.

\section{References}

[1] Rezghi Maleki H, Hamedi M, Kubouchi M, et al. Experimental study on drilling of jute fiber reinforced polymer composites. J Compos Mater 2018; 002199831878237. 
[2] Gupta MK, Singh R. PLA-coated sisal fibre-reinforced polyester composite: Water absorption, static and dynamic mechanical properties. J Compos Mater. Epub ahead of print 2018. DOI: 10.1177/0021998318780227.

[3] Fiore V, Scalici T, Valenza A. Effect of sodium bicarbonate treatment on mechanical properties of flax-reinforced epoxy composite materials. J Compos Mater 2018; 52: $1061-1072$.

[4] Elanchezhian C, Ramnath BV, Ramakrishnan G, et al. Review on mechanical properties of natural fiber composites. Mater Today Proc 2018; 5: 1785-1790.

[5] Sanjay MR, Madhu P, Jawaid M, et al. Characterization and properties of natural fiber polymer composites: A comprehensive review. J Clean Prod 2018; 172: 566-581.

[6] Feldmann M, Heim H-P, Zarges J-C. Influence of the process parameters on the mechanical properties of engineering biocomposites using a twin-screw extruder. Compos Part A Appl Sci Manuf 2016; 83: 113-119.

[7] Cuinat-Guerraz N, Dumont MJ, Hubert P. Environmental resistance of flax/bio-based epoxy and flax/polyurethane composites manufactured by resin transfer moulding. Compos Part A Appl Sci Manuf 2016; 88: 140-147.

[8] Mahboob Z, El Sawi I, Zdero R, et al. Tensile and compressive damaged response in Flax fibre reinforced epoxy composites. Compos Part A Appl Sci Manuf 2017; 92: 118 133.

[9] Bambach MR. Compression strength of natural fibre composite plates and sections of flax, jute and hemp. Thin-Walled Struct 2017; 119: 103-113.

[10] Vieille B, Casado VM, Bouvet C. About the impact behavior of woven-ply carbon fiberreinforced thermoplastic- and thermosetting-composites: A comparative study. Compos 
Struct 2013; 101: 9-21.

[11] Dhakal HN, Zhang ZY, Richardson MOW, et al. The low velocity impact response of non-woven hemp fibre reinforced unsaturated polyester composites. Compos Struct 2007; 81: 559-567.

[12] Belingardi G, Vadori R. Low velocity impact tests of laminate glass-fiber-epoxy matrix composite material plates. Int J Impact Eng 2002; 27: 213-229.

[13] Bondy M, Altenhof W. Low velocity impact testing of direct/inline compounded carbon fibre/polyamide-6 long fibre thermoplastic. Int J Impact Eng 2018; 111: 66-76.

[14] Suresh Kumar C, Arumugam V, Dhakal HN, et al. Effect of temperature and hybridisation on the low velocity impact behavior of hemp-basalt/epoxy composites. Compos Struct 2015; 125: 407-416.

[15] Ahmad F, Hong JW, Choi HS, et al. Hygro effects on the low-velocity impact behavior of unidirectional CFRP composite plates for aircraft applications. Compos Struct 2016; 135: 276-285.

[16] Dhakal HN, Zhang ZY, Bennett N, et al. Low-velocity impact response of non-woven hemp fibre reinforced unsaturated polyester composites: Influence of impactor geometry and impact velocity. Compos Struct 2012; 94: 2756-2763.

[17] Karakuzu R, Erbil E, Aktas M. Impact characterization of glass/epoxy composite plates: An experimental and numerical study. Compos Part B Eng 2010; 41: 388-395.

[18] Atas C, Sayman O. An overall view on impact response of woven fabric composite plates. Compos Struct 2008; 82: 336-345.

[19] Bull DJ, Spearing SM, Sinclair I. Investigation of the response to low velocity impact and quasi-static indentation loading of particle-toughened carbon-fibre composite 
materials. Compos Part A Appl Sci Manuf 2015; 74: 38-46.

[20] Lopes CS, Sadaba S, Gonzalez C, et al. Physically-sound simulation of low-velocity impact on fiber reinforced laminates. Int J Impact Eng 2015; 92: 3-17.

[21] Akil Hazizan M, Cantwell WJ. The low velocity impact response of foam-based sandwich structures. Compos Part B Eng 2002; 33: 193-204.

[22] Hufenbach W, Gude M, Ebert C, et al. Strain rate dependent low velocity impact response of layerwise 3D-reinforced composite structures. Int J Impact Eng 2011; 38: $358-368$.

[23] Evci C. Thickness-dependent energy dissipation characteristics of laminated composites subjected to low velocity impact. Compos Struct 2015; 133: 508-521.

[24] Rajaneesh A, Sridhar I, Rajendran S. Relative performance of metal and polymeric foam sandwich plates under low velocity impact. Int J Impact Eng 2014; 65: 126-136.

[25] Mei H, Yu C, Xu H, et al. The effects of stitched density on low-velocity impact damage of cross-woven carbon fiber reinforced silicon carbide composites. Ceram Int 2016; 42 : $1762-1768$.

[26] Ma H, Li Y, Shen Y, et al. Effect of linear density and yarn structure on the mechanical properties of ramie fiber yarn reinforced composites. Compos Part A Appl Sci Manuf 2016; 87: 98-108.

[27] Strait L., Karasek M., Amateau M. Effect of stacking sequence on the impact resistance of carbon fiber reinforced thermoplastic toughened epoxy laminates. J Compos Mater 1992; 26: 1725-1740.

[28] Hitchen S a., Kemp RMJ. The effect of stacking sequence on impact damage in a carbon fibre/epoxy composite. Composites 1995; 26: 207-214. 
[29] Aktaş A, Aktaş M, Turan F. The effect of stacking sequence on the impact and postimpact behavior of woven/knit fabric glass/epoxy hybrid composites. Compos Struct 2013; 103: 119-135.

[30] Caprino G, Carrino L, Durante M, et al. Low impact behaviour of hemp fibre reinforced epoxy composites. Compos Struct 2015; 133: 892-901.

[31] De Vasconcellos DS, Sarasini F, Touchard F, et al. Influence of low velocity impact on fatigue behaviour of woven hemp fibre reinforced epoxy composites. Compos Part B Eng 2014; 66: 46-57.

[32] Scarponi C, Sarasini F, Tirillò J, et al. Low-velocity impact behaviour of hemp fibre reinforced bio-based epoxy laminates. Compos Part B Eng 2016; 91: 162-168.

[33] Fuoss E, Straznicky P V., Poon C. Effects of stacking sequence on the impact resistance in composite laminates. Part 2: prediction method. Compos Struct 1998; 41: 177-186.

[34] Lebaupin Y, Chauvin M, Hoang T-QT, et al. Influence of constituents and process parameters on mechanical properties of flax fibre-reinforced polyamide 11 composite. $J$ Thermoplast Compos Mater 2017; 30: 1503-1521.

[35] Lachaud F. Contribution à l'analyse multi échelle du comportement mécanique non linéaire matériau des structures composites. HDR, Université de Toulouse, http://core.ac.uk/download/pdf/12042786.pdf(2011).

[36] Lopes CS, Seresta O, Coquet Y, et al. Low-velocity impact damage on dispersed stacking sequence laminates. Part I: Experiments. Compos Sci Technol 2009; 69: 926-936. 


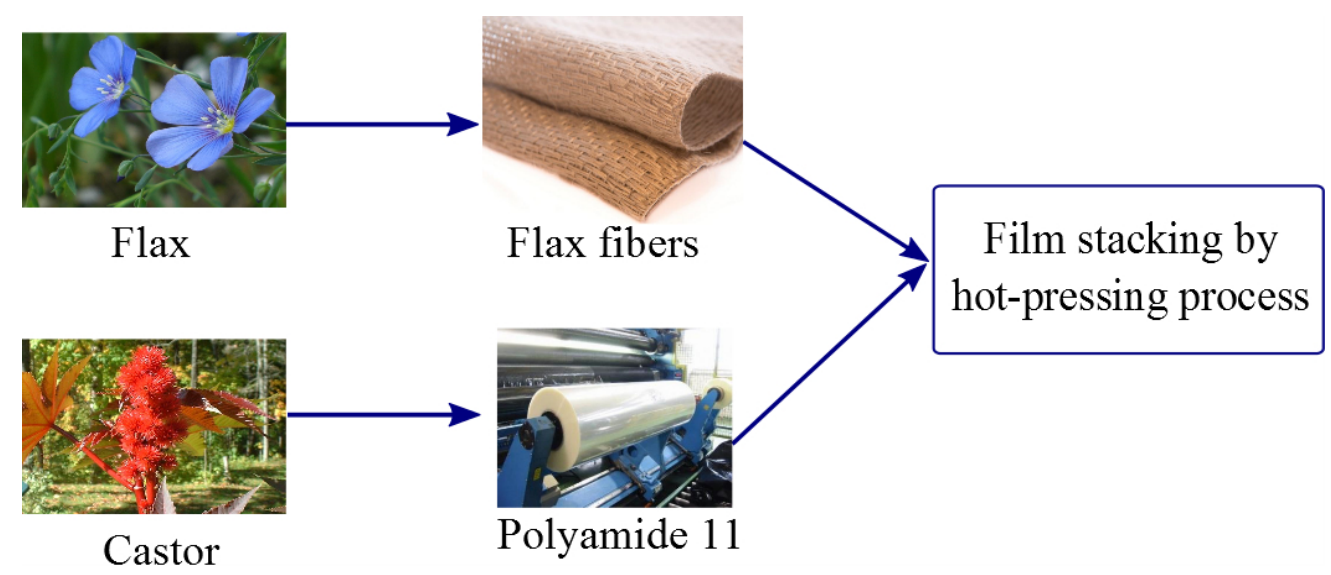

Figure1: From flax and castor plants to flax fibers and Polyamide 11 films.

$277 \times 117 \mathrm{~mm}(96 \times 96 \mathrm{DPI})$ 


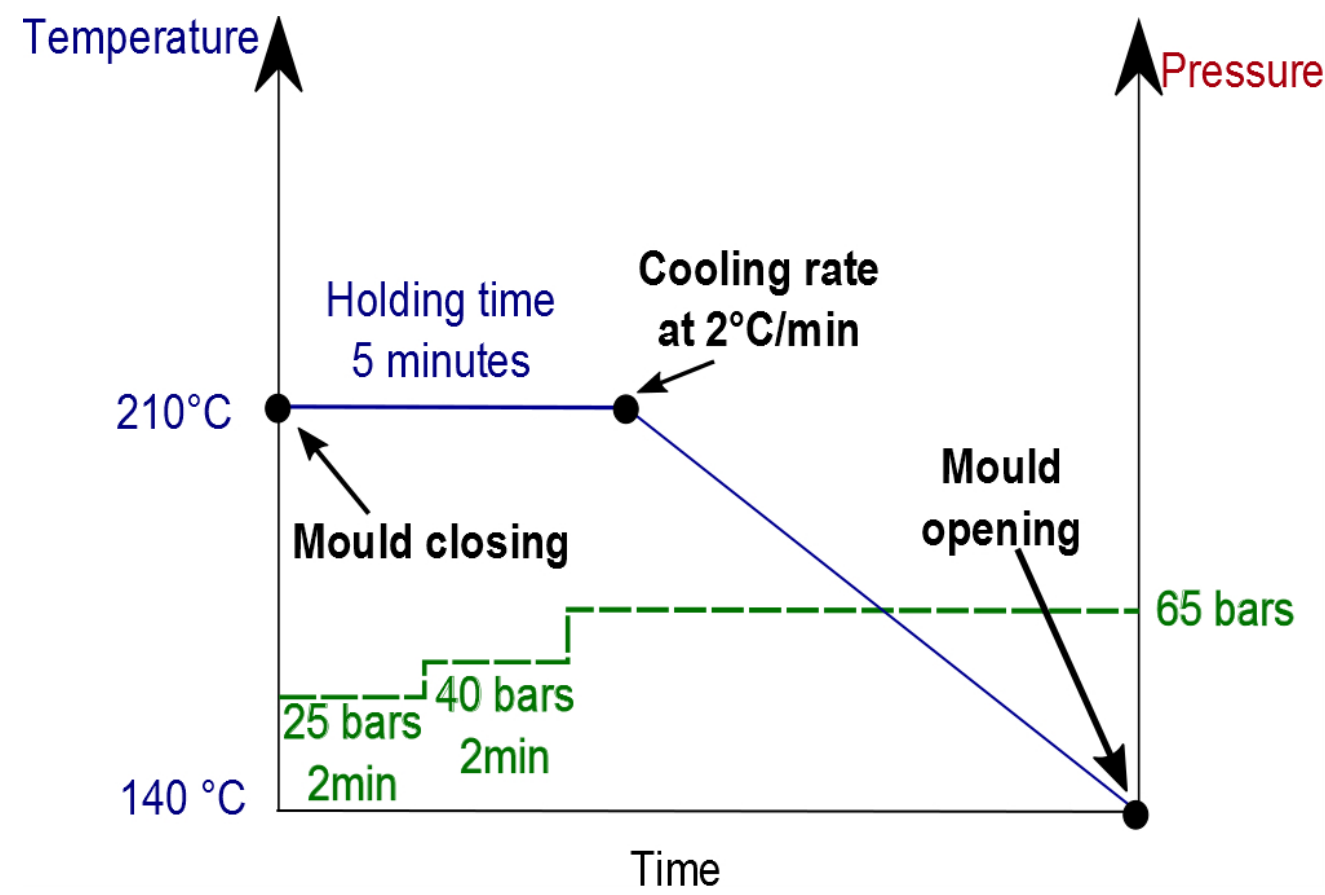

Figure2: Process cycle for elaborating flax/ Polyamide 11 composites.

$266 \times 178 \mathrm{~mm}(96 \times 96 \mathrm{DPI})$ 


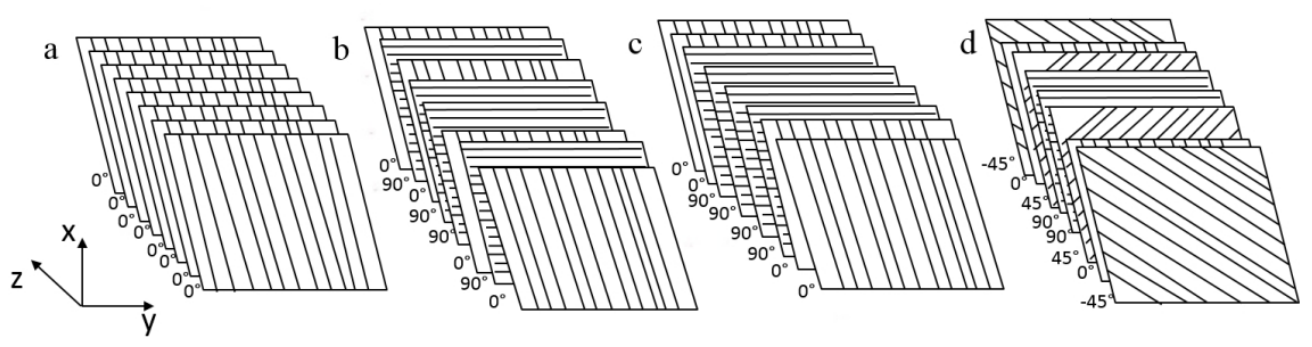

Figure3: Stacking sequences of composites: unidirectional (a), cross-ply (b), sandwich-like (c) and multidirectional $(d)$.

$402 \times 111 \mathrm{~mm}(96 \times 96 \mathrm{DPI})$ 

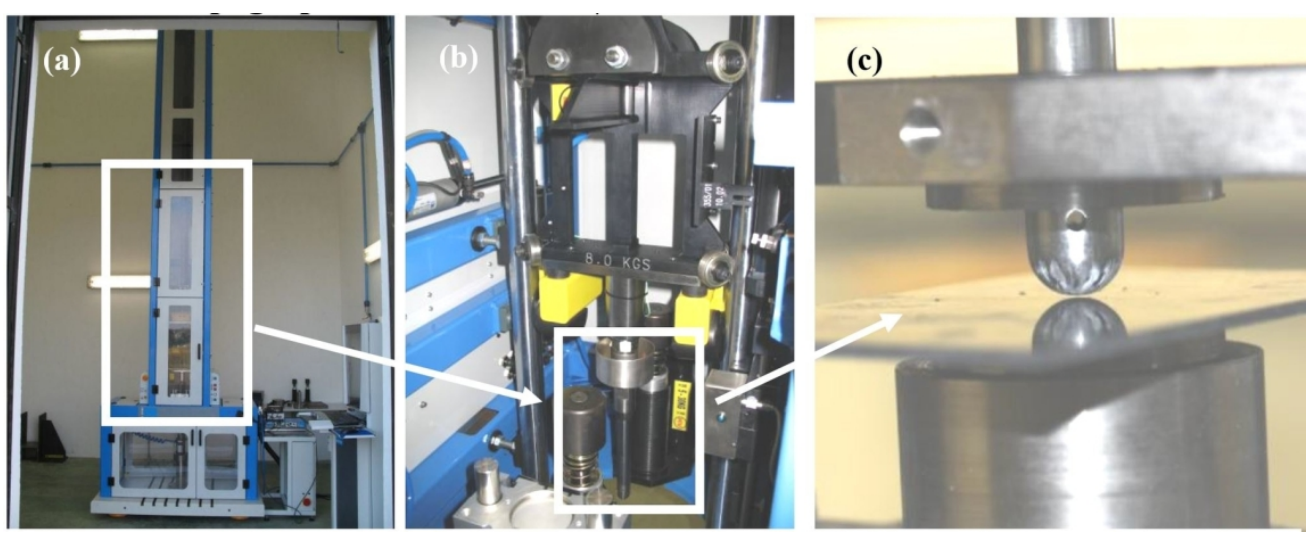

Figure 4: Drop weight impact tower (a), impactor (b) and clamping system (c). $153 \times 61 \mathrm{~mm}(300 \times 300 \mathrm{DPI})$ 


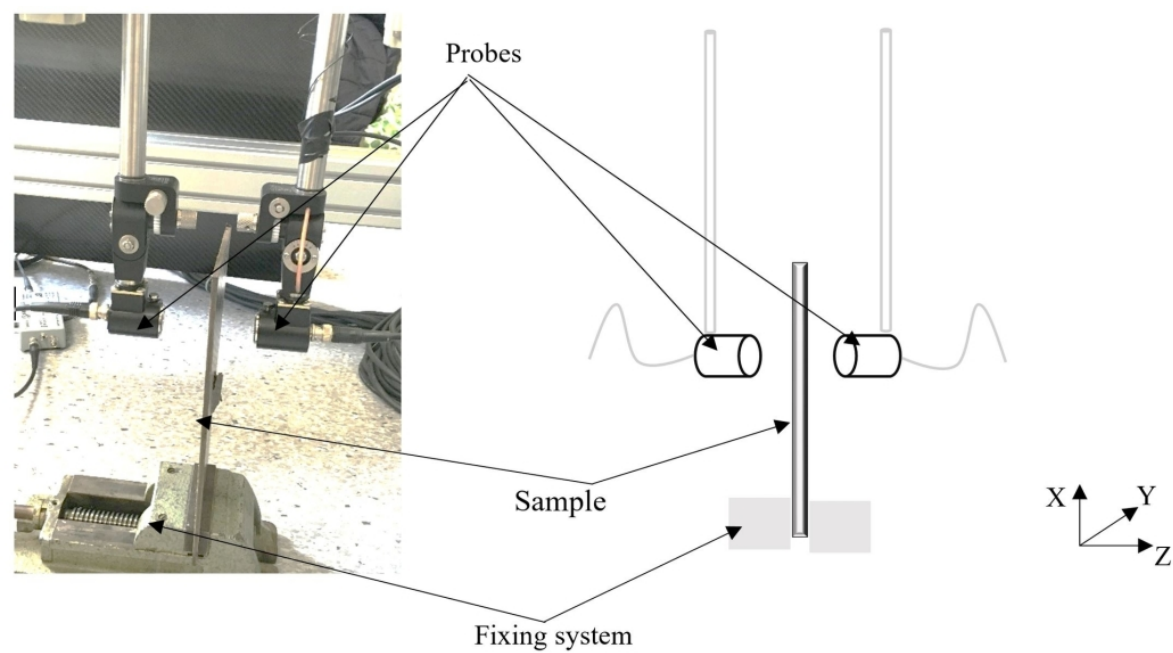

Figure 5: Through air transmission ultra-sound technique system.

$180 \times 94 \mathrm{~mm}(300 \times 300 \mathrm{DPI})$ 

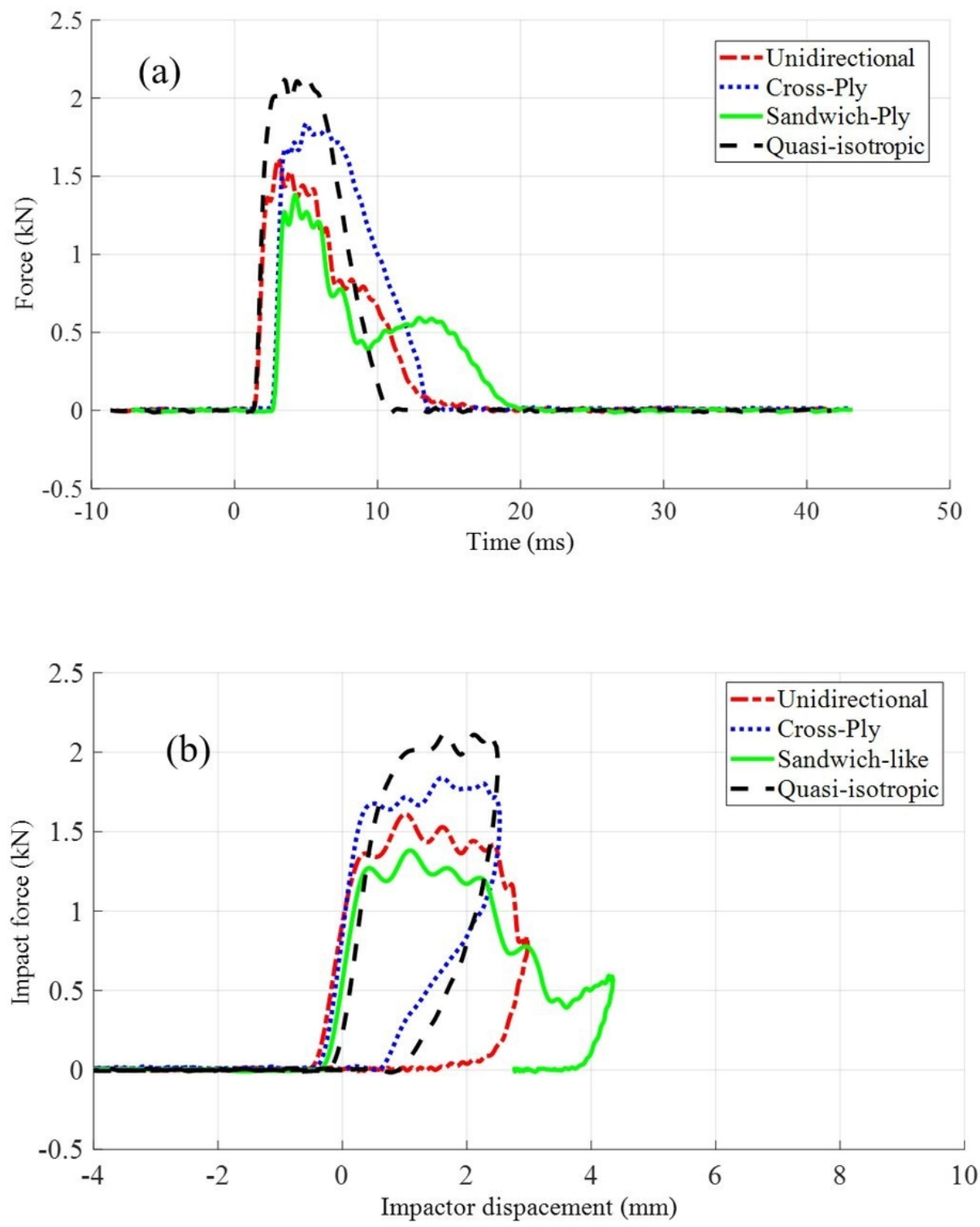

Figure 6: Force-time (a) and force-displacement (b) curves for the different stacking sequences of composites impacted at 3.6J.

$81 \times 100 \mathrm{~mm}(300 \times 300 \mathrm{DPI})$ 

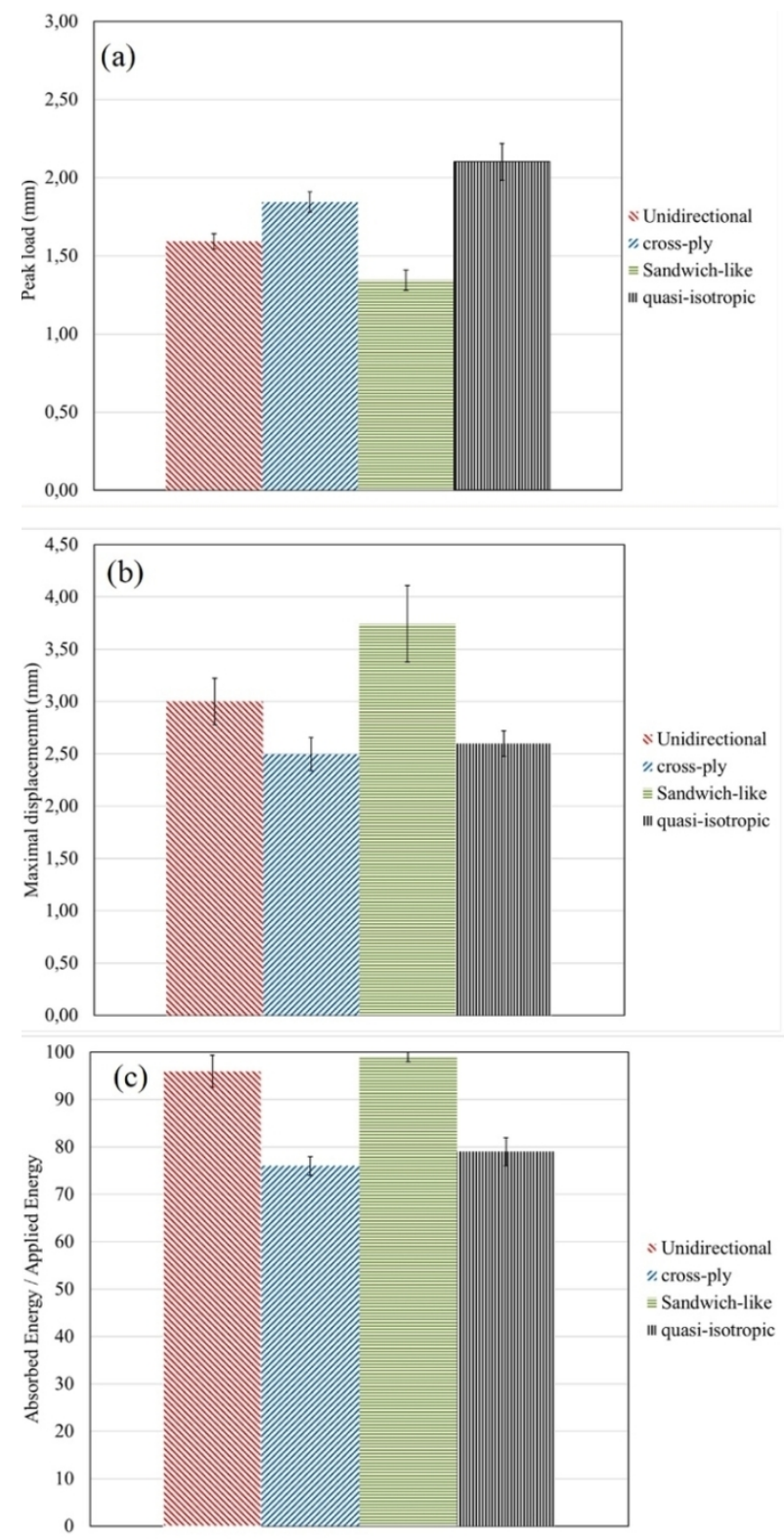

Figure 7: Peak load (a), Maximum displacement of the striker (b) and Absorbed energy applied energy ratio (c) for the different stacking sequences.

$61 \times 122 \mathrm{~mm}(300 \times 300 \mathrm{DPI})$ 
Rear
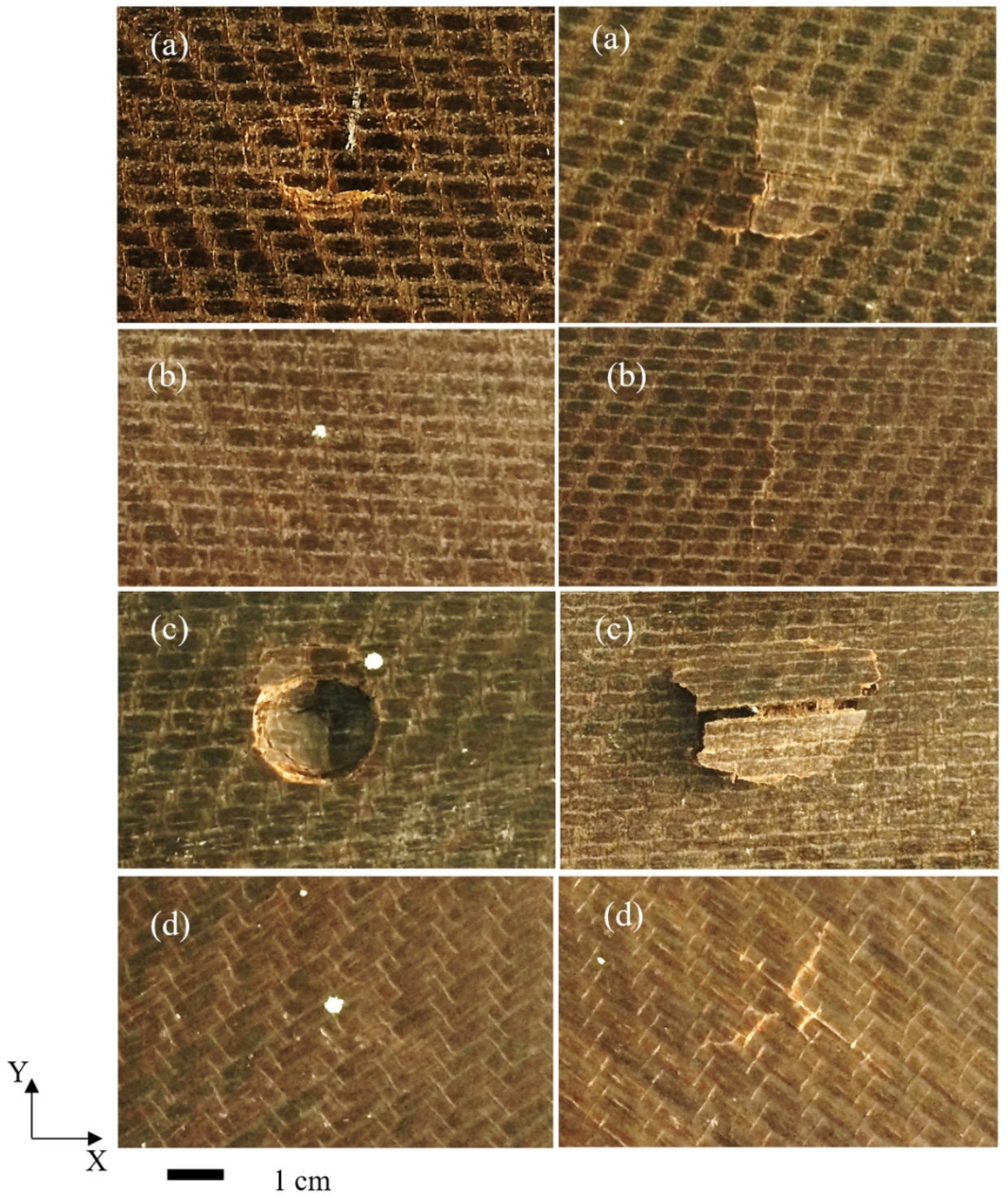


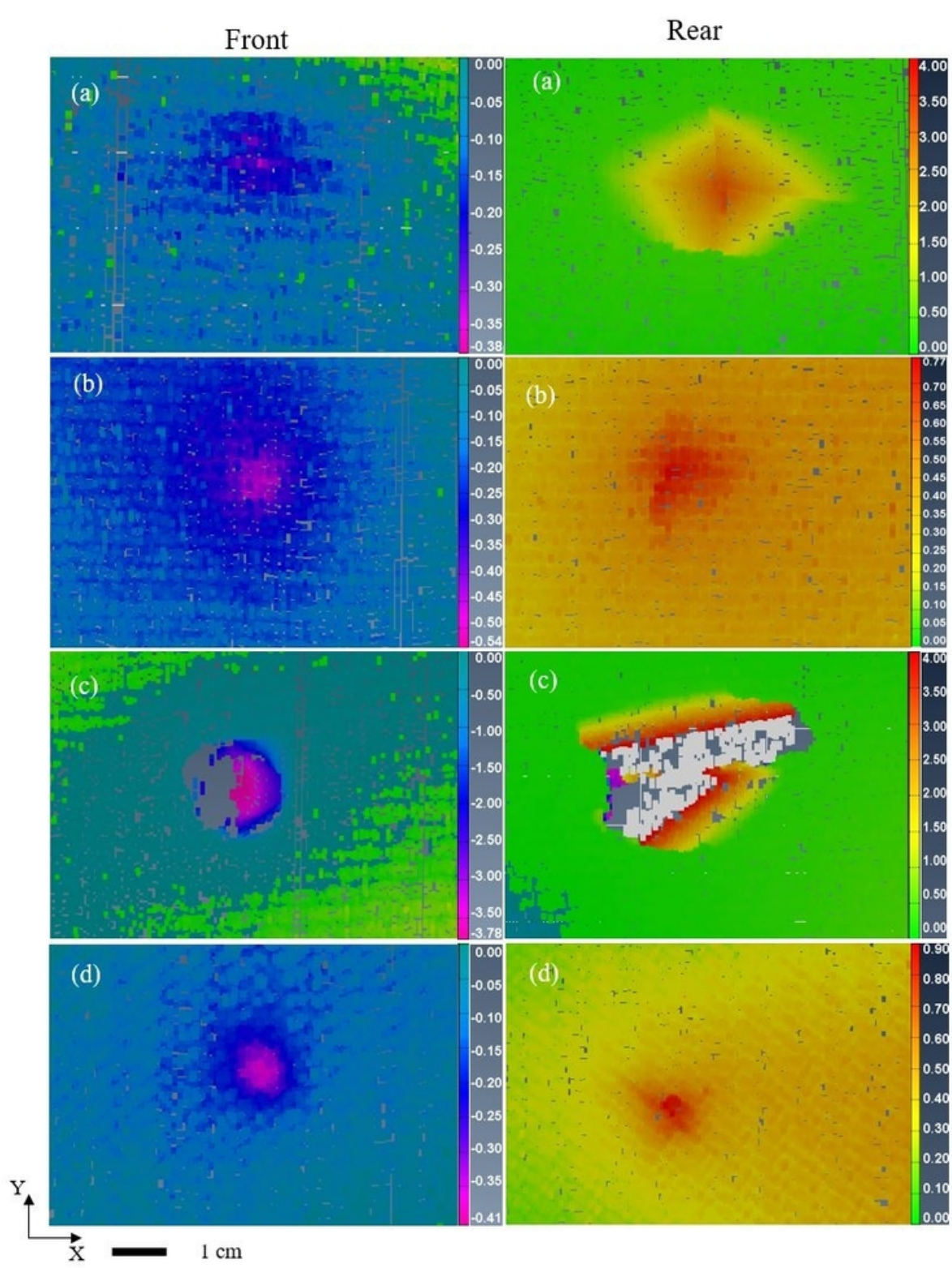

Figure9: Topographic maps ( $\mathrm{mm}$ ) on front and rear faces of unidirectional (a), cross-ply (b), sandwich-like (c) and quasi-isotropic (d) composites impacted at 3.6J.

$66 \times 82 \mathrm{~mm}(300 \times 300 \mathrm{DPI})$ 

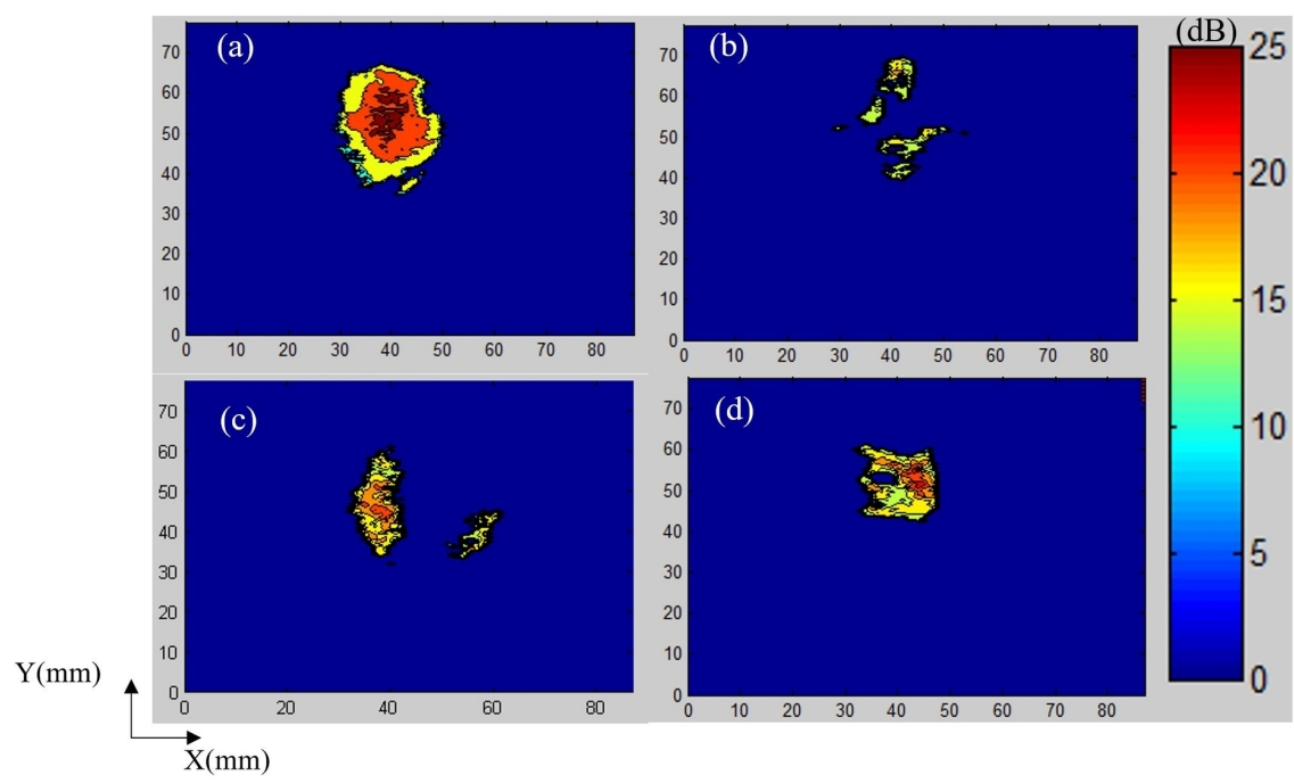

Figure10: Ultrasonic C-scan images of the four types of composites: unidirectional (a), cross-ply (b), sandwich-like (c) and quasi-isotropic (d).

$158 \times 97 \mathrm{~mm}(300 \times 300 \mathrm{DPI})$ 

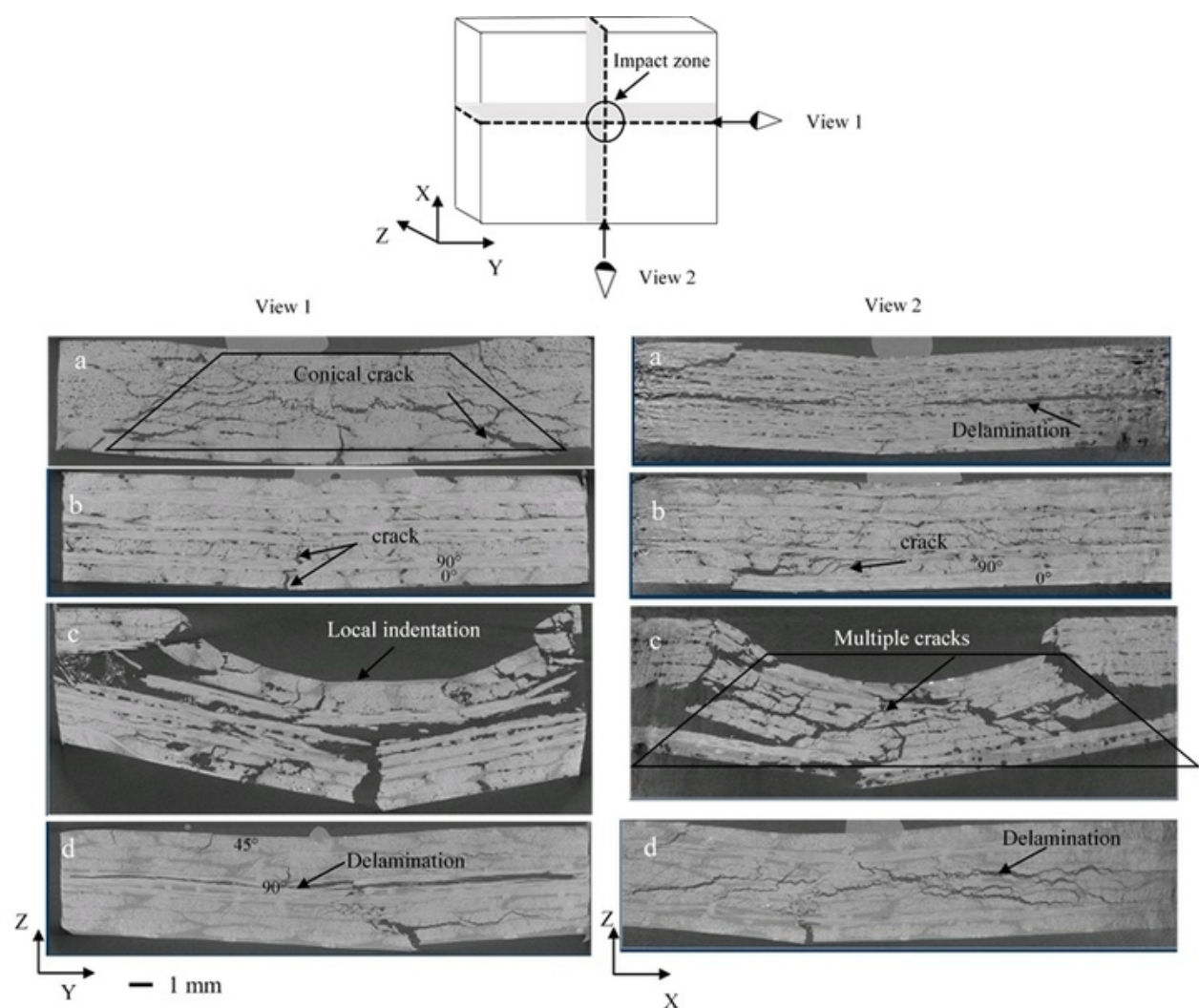

Figure11: Micro-tomography images of the four types of composites: unidirectional (a), cross-ply (b), sandwich-like (c) and quasi-isotropic (d).

$63 \times 52 \mathrm{~mm}(300 \times 300 \mathrm{DPI})$ 